Anuario de Estudios Americanos, 62, 2 , julio-diciembre, 163-185, Sevilla (España), 2005 ISSN: $0210-5810$

\title{
El carácter marginal y arrendatario del sistema de fábrica en paisajes agrarios mexicanos, 1780-1880
}

Humberto Morales Moreno

Universidad de Puebla

El objetivo de este artículo es mostrar algunos ejemplos de las peripecias para la instalación de un moderno sistema fabril en paisajes agrarios mexicanos del altiplano central, desde que Antuñano inauguró su moderna fábrica "La Constancia Mexicana", hasta la llegada del nuevo boom industrialista de 1880. Se pretende demostrar que la preindustria rural y artesanal coexistió sin problemas con sistemas "protoindustriales" y con la instalación propiamente de un sistema fabril. No hubo desplazamientos ni etapas definitivas de transición pero sí una persistente penuria financiera-crediticia que obligó a muchos "hombres de empresa" a arrendar tierras, aguas y molinos para construir o adaptar fábricas modernas como negocio marginal y típicamente arrendatario de otras actividades mercantiles durante el periodo de estudio.

PALABRAS ClaVE: Preindustria, protoindustria, sistema fabril, hombre de empresa siglo XIX, penuria financiera en México, siglo XIX

This paper examines some incidents of a modern industrial system in the Mexican agrarian landscapes of the central highlands, some time before Antuñano inaugurated his modern factory "La Constancia Mexicana"(1835), up until the beginning of the new industrial "boom" of the 1880's. The paper contenas that the rural, handmade "pre-industrial" system coexisted without any problem with a "proto-industrial" extra-regional market system, and also with a very original manufacturing system throughout the XIXth century. There were many transitions to modern factory systems, with a common persistent financialcredit penury that forced many businessmen to lease lands, waters and mills to build or to adapt modern factories as marginal and typically lessee business, as compared with other mercantile activities during a period that runs from 1780 to the 1880's.

KEYWORDS: Preindustrial, protoindustrial, factory system, 19th-century, businessman, financial penury in Mexico, nineteenth century.

El objetivo este artículo es mostrar algunos ejemplos de las peripecias para la instalación de un moderno sistema fabril en paisajes agrarios mexicanos del altiplano central, desde que Antuñano inauguró su moderna fábrica "La Constancia Mexicana", hasta la llegada del nuevo boom industrialista de 1880 . Se pretende demostrar que la preindustria rural y artesa- 
nal coexistió sin problemas con sistemas "protoindustriales" y con la instalación propiamente de un sistema fabril. No hubo desplazamientos ni etapas definitivas de transición pero sí una persistente penuria de carácter financiero-crediticia que obligó a muchos "hombres de empresa" a arrendar tierras, aguas y molinos para construir o adaptar fábricas modernas como negocio marginal y típicamente arrendatario de otras actividades mercantiles durante el periodo de estudio. En este sentido, la región cerealera del valle de Atlixco, al sudoeste del valle Poblano-Tlaxcalteca, reviste un interés especial en esta historiografía de los intentos de industrialización en paisajes agrarios del altiplano central mexicano. Permite ejemplificar con profundidad esta paulatina transformación del paisaje agrario de las haciendas en molinos y fábricas a lo largo del siglo XIX y los complicados mecanismos de acumulación de capital y estrategias de negocios que conservaron una fuerte continuidad en el siglo que va de las reformas borbónicas a la expansión del llamado porfiriato (1876-1910).

\section{Paisaje agrario novohispano y manufacturas: 1532-1780}

Desde 1534 se conoce la real cédula ${ }^{1}$ que permitió regularizar y ampliar la dotación de tierras del valle de Atlixco para labradores españoles residentes en la ciudad de Puebla. Es necesario recordar que la ciudad de Puebla se fundó con el objeto de constituirse en centro de control político y administrativo del tráfico mercantil de y hacia la metrópoli. Al no otorgarse encomiendas en la primera fundación de la ciudad de Puebla, muchos españoles que se creyeron con derechos, residentes en el lugar, solicitaron dicha dotación de tierras desde la segunda fundación de la ciudad en 1532. No olvidemos que, siguiendo a Silvio Zavala, ante las peticiones de suprimir la encomienda en las regiones de Huejotzingo y Tepeaca para facilitar el repartimiento, una buena parte de los nuevos trabajadores del valle surgirían de los pueblos sujetos de Cholula y Tlaxcala. ${ }^{2}$ Toda esta historia de la reorganización espacial del valle se inicia con las dificultades climatológicas para cultivar el trigo que sufrieron los indios repartidos en la nueva ciudad

1 Véase Real Cédula dictada en Toledo por el Rey Carlos I de fecha 27 de agosto de 1534 , asentada en el Cabildo Metropolitano de Puebla N. ${ }^{\circ}$ 1, Archivo Histórico del Ayuntamiento de Puebla, citada por Silva Andraca, Héctor: Atlixco en la Macrohistoria, Ayuntamiento de Atlixco, 1979, págs. $42-50$.

2 Véase Zavala, Silvio: El servicio personal de los indios en la Nueva España, 1521-1550, El Colegio de México, México, 1984, págs.301-306. 
española de Puebla, dadas las continuas heladas y las dificultades de irrigación. Ya Francisco de Orduña, encomendero de Cuauhtinchan hacia 1531, recibía tributos de los habitantes en siembras de trigo. En las tasaciones de ese año se mencionaban 16.5 fanegas de trigo. La urgencia de colonización para el abasto de trigos convirtió al valle de Atlixco en el futuro granero de la Nueva España, a través de un singular mandato de otorgamiento de tierras "aparentemente baldías" y en un radio circunscrito por la presencia de los señoríos indígenas de Cholula, Calpan y Huejotzingo, que sancionaron de alguna forma la adjudicación de tierras desde 1532.

Este asentamiento no siempre coincidió con lo que con el tiempo conformaría la actual ciudad de Atlixco. Es importante remarcar que el conquistador Diego de Ordaz heredó las encomiendas de Cortés en Calpan y Huejotzingo y que la presencia de cultivos y de la ganadería era ya importante años atrás del primer repartimiento de 1532. También debemos recordar que acequias de origen prehispánico eran ya conocidas por los señoríos indígenas, por lo que la importancia agrícola de la zona estaba ya acreditada mucho antes de la expansión de los labradores españoles avecindados en la ciudad de Puebla.

$\mathrm{Al}$ incorporarse el valle a la nueva geografía económica de Puebla como tributario de parte de las 8 mil fanegas de trigo que la abastecían, entre 1532-1600, quedó establecida también la paulatina lucha que los señoríos de Huejotzingo, Cholula y Calpan entablarían, aparentemente desde las incursiones de Francisco de Montealegre en 1537, para defender sus tierras de la fuerte expansión española más allá de los límites territoriales pactados en la cédula de 1534 .

Entre 1776 y 1787 la intendencia de Puebla contaba con 17 alcaldías mayores (en la ordenanza original Cholula y Huejotzingo están juntas), un gobierno, el de la ciudad de Tlaxcala, y un corregimiento, el de Chietla. La alcaldía mayor de Atlixco tenía el rango de ducado y bajo su jurisdicción se encontraban las Alcaldías Mayores de Tepeaca y Huauchinango. El antiguo partido de Tochimilco perteneció a la jurisdicción de la Alcaldía Mayor de Cuautla Amilpas. ${ }^{3}$

El ducado tenía bajo su control a seis cabeceras de ayuntamiento con un total de 16 partidos, con aproximadamente 607 pueblos. La Villa de Atlixco tuvo bajo su jurisdicción administrativa a los partidos de: Calpan, Tianguismanalco, Acapetlahuacan, Atzitzihuacan, Huaquechula y Cuayuca.

3 Gerhard, Peter: A guide to the Historical Geography of New Spain, Cambridge,1972 y Commons, Áurea: Las Intendencias de la Nueva España, UNAM, México, 1993, págs. 35-43. 
Entre estos partidos se ubicaban 35 pueblos, así como 7 parroquias, 5 conventos y 6 curatos. Entre 1787-1792, 22 haciendas, 15 ranchos y 3 molinos de trigo estaban en la jurisdicción del partido de Atlixco; 22 haciendas, 10 ranchos y 20 pueblos en la jurisdicción de Huaquechula; 12 haciendas, 7 ranchos y 10 pueblos en la jurisdicción de Calpan. Hacia 1792, el partido de Atlixco no tenía pueblos bajo su tutela, de manera que del total de haciendas y ranchos, 56 y 32 respectivamente, el $40 \%$ y el $50 \%$ estaban bajo control de la cabecera. Los 20 pueblos registrados en Huaquechula eran de indios puros y de los 10 de Calpan, 7 eran de indios puros. Además, algunos caciques y principales, así como pueblos de indios, tenían ranchos y haciendas bajo su jurisdicción. Tales son los casos del rancho de Hueyotengo, de los indios de Tlapala y el rancho de San José Tepoxtlán del gobernador indio de San Juan Tianguismanalco, Don Sebastián Osorio. También controlaban los indios de Calpan el rancho de San Pedro Atlixco. Los de Huaquechula controlaban 4 haciendas y 2 ranchos. Para los años de los informes del visitador Maneyro, el valle era ya un asentamiento de gran población indígena. De un total de 28,388 almas, 23,368 fueron indios y 1,766 españoles.

\section{CULTIVOS PRINCIPALES EN LAS SUBDELEGACIONES DE LA INTENDENCIA DE PUEBLA: 1787-1792}

Subdelegaciones:

Cultivos Principales:

Atlixco, Chiautla y Huejotzingo.

Trigo

Amozoc, Huauchinango, Huayacocotla,

Tecali, Tehuacán, Tepeaca, Tochimilco y

Totimehuacán.

Izúcar de Matamoros.

Chietla y Zacatlán.

Igualapa, Tehuacán y Tlapa.

Chiautla y Tehuacán.
Frijol y maíz

Caña de azúcar

Frutas

Grana cochinilla

Salinas $^{4}$

Al parecer los repartos de tierras desde el siglo XVI fueron más o menos equitativos. La antigua frontera del maíz indígena sobrevivió durante

4 Palacios, Enrique Juan: Puebla, su territorio y sus habitantes, Fomento, México, 1917. También Puebla a través de los siglos, México, García Valseca, 1962 y Commons: Las Intendencias..., pág. 127. 
toda la época virreinal y en buena medida fue el detonante de la ganadería porcina, que en la ciudad de Puebla creó organizaciones como la Mesta. Hacia finales del XVIII la ganadería había impulsado la industria del curtido de pieles, hasta que el agotamiento en la matanza provocó una crisis que dejó prácticamente a la subdelegación de Matamoros como la única importante en esta industria.

La manufactura textil poblana también se destacó desde muy temprano. Son famosas las historias de la industria de la seda, la lana y del algodón a través del sistema de obrajes, que tejían en la capital terciopelos, damascos y mantas que llegaban hasta el Perú. Las prohibiciones ya estudiadas por otros autores del siglo $\mathrm{XVII}^{5}$ dieron al traste con la industria pañera de la intendencia y también con la industria de la loza, en consecuencia el intendente Manuel de Flon consignó 40 establecimientos en 1793 y 12 en $1804 .{ }^{6}$ Puebla contó también con manufacturas de vidrio, jabón, sombreros y artesanías de tecali (ónix).

En el informe al virrey Revillagigedo de 1794, de Flon registró la siguiente actividad económica "industrial" de la Intendencia:?

\section{SUBDELEGACIONES Y ACTIVIDAD "INDUSTRIAL" EN LA INTENDENCIA DE PUEBLA EN 1794}

\begin{tabular}{ccc} 
Subdelegación: & Rama Industrial & $N .^{\circ}$ Establecimientos \\
\hline Alcaldía Mayor de Puebla & Paños de lana & 2 \\
& Vidrio & 3 \\
& Lozas (fina y vulgar) & 30 \\
& Jergas algodón & 9 \\
Sombreros & 13 \\
Jabón & 40 \\
Telares sueltos & 1177 \\
Molinos & 14
\end{tabular}

5 Carabarín Gracia, Alberto: El trabajo y los trabajadores del obraje en la Ciudad de Puebla. 1700-1710, CIHS-UAP, Puebla, 1982. Commons: Las Intendencias..., pág.128. Lizt Arzubide Germán: Puebla, síntesis histórico geográfica del Estado, SEP, México, 1946, pág. 29. Quintana, Miguel A.: "Papel histórico de Puebla en el progreso industrial de la Nueva España y de México", Boletín de la Sociedad Mexicana de Geografía y Estadística, t. 62, n. . 2, México, 1946.

6 Véase la famosa y muy citada del Intendente de Flon: Archivo General de la Nación, Descripción de la Intendencia de Puebla, 1804, Ramo Civil, 2092, 2, 51-100.

7 Archivo General de la Nación, Intendente De Flon: Informe, 1794, Ramo de Historia, 74, 411-414. 


\begin{abstract}
SUBDELEGACIONES Y ACTIVIDAD "INDUSTRIAL" EN LA INTENDENCIA DE PUEBLA EN 1794 (continuación)
\end{abstract}

Subdelegación:

\begin{tabular}{ccc}
\hline TehuacánTrapiches de caña & 2 & 3 \\
& Molinos & 6 \\
\hline Acatlán & Trapiches de caña & 4 \\
\hline Atlixco & Molinos & 11 \\
\hline Chiautla & Trapiches de caña & 1 \\
\hline Chietla & Molinos & 1 \\
\hline Cholula & Ingenio azucarero & 5 \\
\hline Ihualapa & Molinos & 5 \\
\hline Izúcar de Matamoros & Trapiches de caña & 4 \\
\hline Tecali & Ingenios azucareros & 1 \\
\hline Huejotzingo & Molino & 3 \\
\hline San Juan de los Llanos & Molinos & 45 \\
& Telares sueltos & 2 \\
\hline Tlapa & Molinos & 1 \\
\hline Tepeaca & Molinos & 3 \\
\hline Teziutlán & Molinos & 5 \\
\hline Tochimilco & Trapiches de panela & 1 \\
\hline & Molinos & \\
\hline
\end{tabular}

Estamos hablando de manufactura regional con cierto grado de mecanización. De los 38 molinos contabilizados debemos tener la precaución de distinguir posibles trapiches de azúcar en el suroeste poblano que se registraron muy probablemente como molinos. Podrían incluirse ciertos oficios artesanales como la orfebrería, en particular la batihojería poblana de gran prestigio, y la herrería de forja de balconería típica de Amozoc. El ambiente preindustrial estaba claramente establecido en la Intendencia desde mediados del siglo XVIII.

Ahora bien, por un lado en la ciudad de Puebla se desarrolla la industria textil en el contexto de un paisaje urbano con crisis de mercados, epidemias y hambrunas, donde la necesidad y la pobreza obligaron a los grandes 
comerciantes poblanos a invertir en la manufactura no sólo para contener el flujo migratorio intrarregional hacia la ciudad (empleo del trabajo doméstico y a domicilio), sino también asegurar de esta forma un mercado de productos manufacturados. Por otro lado, la "proto-industria" virreinal en paisajes agrarios, como el del valle de Atlixco, nos guarda todavía muchos secretos y sorpresas, pues consideramos que no es posible comprender la súbita expansión de un corredor fabril de fines del siglo XIX en franca competencia con Puebla, sin analizar en profundidad la enorme continuidad, a pesar de la brusquedad de los cambios políticos del siglo XIX, de las formas de intercambio mercantil del último período borbónico. ${ }^{8}$

La ocupación hacia mediados del siglo XVI de las mejores tierras del valle de Atlixco por los agricultores españoles provocó la necesidad de establecer un equilibrio económico y político entre hacendados y rancheros ya prósperos al comenzar el siglo XVII. De acuerdo con la composición de tierras de 1643, la distribución de tierras y aguas en el valle facilitó el crecimiento de una agricultura intensiva. Los agricultores establecidos en la parte central del valle firmaron una representación advirtiendo que dichas tierras tenían una ocupación máxima gracias a su gran fertilidad y a la ausencia casi absoluta de tierras baldías. ${ }^{9}$ Entre 1640 y 1727 algunas haciendas trigueras registraban ya en sus inventarios una buena infraestructura de aperos agrícolas, ganado menor y mayor, animales de granja, trabajadores permanentes que, aunque en número reducido al interior de las haciendas, constituyeron el pilar de la organización del trabajo agrícola que hizo famoso al valle como el primer granero de Nueva España en producción de trigos a lo largo de los siglos XVI y XVII. Las agro-industrias de Atlixco reportan sus orígenes en los informes de hacendados, como el de la hacienda "Santo-Domingo" donde se menciona la existencia de molinos para la producción de harinas por lo menos desde 1640. Alrededor de la producción de trigo y de los molinos se desarrollaron una serie de actividades artesanales y comerciales, sobre todo a fina-

8 Véase Miño Grijalva, M: "Proto-industria colonial ?", en Historia Mexicana, vol. XXXVIII, núm. 4 abril-junio, México, 1989, págs. 793-818 y "Capital comercial y trabajo textil. Tendencias generales de la proto-industria colonial latinoamericana", en Revista latinoamericana de historia económica y social, núm. 9, 1er semestre, 1987, págs. 59-79. Para el balance historiográfico sobre el uso del concepto en las sociedades desarrolladas véase: Cailly, Claude: "Contribution à la définition d'un mode de production proto-industriel", en: Histoire et mesure. VIII -1/2 pp. 19-40. (1993).

9 Véase Torres, Mariano: Establecimiento y alcances de una empresa agroindustrial en el Valle de Atlixco. 1867-1910, Tesis de Maestría en Historia, UAM-IZT, México, 1985; Paredes, Carlos: Agricultura y Sociedad en Atlixco, CIESAS-INAH, México, 1982. 
les del XVII y a lo largo del XVIII. El establecimiento de los "obrajes" de las harinas para Atlixco, desde 1617, desató la proliferación de talleres artesanales que crecieron estimulados por el mercado paralelo que la harina de exportación generó entre los comerciantes-aviadores, hacendados, arrieros transportistas y las comunidades de indios, abastecedoras temporales de familias de trabajadores.

A pesar de la crisis de mercados de Puebla para finales del XVIII, la importancia de las harinas de Atlixco llegó a ser tal que para mediados del siglo XIX el consejo municipal de la villa pidió que el famoso "camino del sur" se financiara con los fondos que reportaba la producción de harinas de Atlixco, al igual que pasaba en Puebla y en México. Se anotaba en el artículo 1 del decreto del cuatro de enero de 1832: "El gobierno cuidará de que la parte del camino del sur que corresponde a la municipalidad de Atlixco, se mantenga siempre compuesta del fondo municipal que reportaba la harina en dicho valle, desde antes de la independencia". ${ }^{10}$

La riqueza del valle había incrementado, para los albores del XVII, su dependencia comercial con Puebla, monopolizadora principal del comercio local de granos y de materias primas por conducto de una red todavía poco estudiada de comerciantes intermediarios. En la región central de Puebla los hacendados solían vivir en el área urbana de la ciudad capital. En Atlixco, dadas las características de la distribución espacial de las mercedes de tierras y encomiendas, a medida que la prosperidad de la región se hacía más evidente, sobre todo en las tierras con régimen de irrigación, los propietarios tendieron a acercarse y un buen número de ellos terminó por establecerse no sólo en el cuadro "urbano" de Atlixco sino en el paisaje agrario de las mismas haciendas y ranchos.

No es necesario insistir en las posibles causas de la decadencia mercantil de Puebla y su región para finales del siglo XVIII, pues éstas han sido estudiadas con detalle por diversos autores. ${ }^{11}$ Agregaríamos solamente que al sufrir el valle de Atlixco las consecuencias de su articulación mercantil con Puebla, la decadencia de la capital de la Intendencia permitió que su acercamiento a los grandes mercados del centro-occidente de México

10 Véase informes sección Gobierno. Archivo Municipal de Atlixco. 1836-1839. Se hace mención del problema del financiamiento desde 1832.

11 Véase Contreras, Carlos: "La ciudad de Puebla en el siglo XIX", en Puebla de la colonia a la revolución, UAP, México, 1987; Cuenya, Miguel: "Puebla en su demografía. 1650-1850", en: Contreras: Puebla..., págs. 9-72; Garavaglia y Grosso: Las alcabalas novohispanas, A. G. N., México, 1984; Carabarin, A.: "El trabajo y los trabajadores del obraje en la Ciudad de Puebla. 1700-1710", en Cuadernos de la Casa Presno, UAP, México, 1984. 
conservara la producción agro-industrial de herencia virreinal, manteniendo puentes ecológicos y sociales que progresivamente anunciarían la formación de estas "industrias nuevas" de extracción rural, de la segunda mitad del siglo XIX.

Por otro lado, en pleno siglo de crisis para Puebla, las actividades de los españoles en el valle de Atlixco se incrementaron notablemente. En 1768 se inauguró en Atlixco la "Real Fábrica del Monopolio de la Pólvora", aprovechando los suelos salitrosos y sulfurosos de la zona volcánica. Entre 1784-1841, como ya mencionamos más arriba, la construcción del empedrado del "camino del sur" atrajo la atención especial del Cabildo atlixquense y poblano. Se intentó consolidar el viejo sueño de unir Puebla y Atlixco de manera expedita para aprovechar de mejor forma el mercado del pacífico hasta Acapulco, donde el Galeón de Manila desembarcaba mercancías que llegaban a Puebla utilizando la intermediación geográfica de Matamoros-Atlixco, como tierras intermedias del eje geográfico neovolcánico. De manera conjunta con las explotaciones agrícolas de las haciendas, la expansión del ganado lanar creció también en forma considerable. Aunque todavía mal estudiada, es indudable que la ganadería entró en crisis cuando las prohibiciones de paños poblanos para el mercado intracolonial y de exportación ultramarina, y la fuerte competencia de los obrajes laneros de Querétaro y Acámbaro hicieron poco menos que rentable el desarrollo de las manufacturas de lana fuera del pequeño consumo local de haciendas y pueblos de la región.

El informe de $1792^{12}$ registra cinco molinos de harina de trigo en el valle. Es evidente que el mercado extrarregional fue mucho más grande en comparación con la capacidad instalada, lo que explica que muchas haciendas se encargaran de la molienda de sus trigos o, en su caso, que éstos fueran enviados a Puebla para ser molidos en la ciudad, cuya capacidad era claramente superior. ${ }^{13}$ Es importante también tomar en cuenta que los molinos de trigo del valle formaban parte de instalaciones agrícolas mayores. Poco importaba que se ubicaran a las afueras de la villa, cerca de las corrientes fluviales, los propietarios contaban con tierras adyacentes o éstas se integraban a la vida económica de la hacienda.

En este panorama, surgieron los obrajes y talleres del lino, el cáñamo, la seda y el algodón. Estas manufacturas se extendieron con las reales órde-

12 Véase Maneyro, Ignacio: Informe, 1792.

13 Véase Tamayo, Jorge: El molino de Huexotitla, C.E.H.B.P., sobretiro, Puebla, 1955. Siliceo, Manuel: Memoria del Ministerio de Fomento, México, 1857. 
nes de 1727 y se favorecieron con la paulatina liberación del comercio intracolonial en los tiempos de Carlos III. ${ }^{14}$ A partir de 1772 se libera la producción de telas de algodón pintadas (los orígenes de un cierto tipo de taller o pequeña fábrica de "indianillas"). Ya en estos años detectamos la presencia de maestros artesanos de origen español provenientes de Puebla que vendrían a impulsar la manufactura del hilado y tejido de algodón en el entorno agro-industrial de las haciendas. ${ }^{15}$

A pesar de que el reformismo borbónico estimuló las actividades económicas que podrían ayudar a fortalecer la economía metropolitana, oponiéndose claramente al fomento de la competencia de los tejidos y pintados novohispanos, era tal la fuerza del mercado regional y extrarregional, que reales órdenes de 1773 liberaron la venta de manufacturas de lana, lino y cáñamo fabricados en la región. Los obrajes de la lana atravesaron por una etapa muy difícil desde el siglo XVII en Puebla. En el siglo XVIII la expansión de los textiles de algodón, que no oponían competencia a los "telares de castilla" (producción de paños finos de lana), contó con mayor suerte, a tal grado que el virrey Revillagigedo se permitió sugerir en una de sus instrucciones reservadas que prefería desarrollar el cultivo de las materias primas y la instalación de fábricas de tejidos rústicos de algodón para que la Corona pudiera competir con los mercados de Francia y Flandes con textiles a menor precio. ${ }^{16}$ Comienza, entonces, en pleno siglo XVIII un camino a la fábrica en un paisaje "proto-industrial" sui géneris, pues la producción manufacturera se destinaba a mercados extrarregionales.

Hasta antes de la colonización del valle atlixquense, el maíz fue el cultivo fundamental. La "resistencia" del pasado indígena no permitió que la implantación del cultivo europeo del trigo terminara del todo con el consumo mayoritario del maíz. Los cultivos mixtos fueron comunes y, hoy en día, el maíz ha vuelto a ser el producto principal.

En el último tercio del siglo XVIII el partido de Atlixco contaba ya con 56 haciendas y 26 ranchos esparcidos en un territorio que registraba 24 pueblos y la villa de Atlixco, como cabecera principal. Al parecer, según el registro de la época, había 55 propietarios entre indios, testamentarías y

14 Archivo Municipal de Atlisco, Puebla, (A.M.A.), 1774. Los lienzos de lino pintados se desarrollaron entre 1727-1770.

15 A.M.A, Gobierno, años 1746-1774.

16 La referencia a esta instrucción se encuentra en: Cervantes, E.A.: Sinopsis histórica del Distrito de Atlixco, Imp. Artes y Oficios, Puebla, 1922 Véase también Díaz Solís, Espiridión: Atlixco. Datos históricos, geográficos y estadísticos, Puebla, 1938. Cervantes, E. A.: Documentos para la historia de Puebla, SMGE, México, 1925. 
hacendados/comerciantes. El partido comprendía la villa de Atlixco con su periferia agrícola, un gran pueblo de indios llamado Acapetlahuacán, cuatro conventos con tierras y uno de monjas clarisas. Siendo esencialmente una villa de españoles, su principal mercado era el de la ciudad de Puebla y con gran dificultad, dadas las malas condiciones de la distancia entre los dos lugares. Además la propia cercanía "ofendía" el desarrollo de su propio espacio económico, pues ya el visitador Ignacio Maneyro decía:

"El comercio de esta villa no corresponde al mérito de su población, (...) las tiendas que hay, que no son pocas, sólo están surtidas de lo necesario para graduarse por puramente mestizas con algunos géneros de lencería y ropa común: en esta parte le ofende la inmediación de Puebla, de donde se proveen sin utilidad de su patrio suelo, pues hasta los zapatos y hechuras de otros oficios, no los consideran de provecho las familias de distinción, si no son de aquella ciudad, (...) el único ramo de industria que sostiene a los vecinos de Atlixco es la agricultura". ${ }^{17}$

Los cinco curatos adicionales al de la villa administraban la vida espiritual de 34 pueblos de indios. De las 56 haciendas censadas por Maneyro, 34 formaban parte del espacio agrario de la villa de Atlixco. El espacio administrativo regional contaba a la vez con el tenientazgo de Calpan y el pueblo indígena de Huaquechula, el cual gozaba de consideraciones especiales por la conquista, en la que colaboró ampliamente del lado de las huestes cortesianas.

En este contexto agrario, los indios controlaban en propiedad 16 pueblos sujetos de Huaquechula, 5 pueblos de Calpan y 4 compartidos con "gente de razón", además de buena parte de las tierras de Acapetlahuacán, en la jurisdicción de la villa principal. Los indios controlaban en propiedad también 4 haciendas de Huaquechula y 5 ranchos, 2 en Huaquechula y 3 en Calpan. Las órdenes religiosas controlaban 15 unidades productivas, y 41 hacendados controlaban 58 unidades productivas agrícolas. Sólo 14 de ellos poseían entre 4 y 2 unidades y el resto, una sola y uno que otro cajón de comercio en la villa de Atlixco. Sólo dos de ellos tenían rancho y molino de trigo junto con una o dos propiedades más y dos un rancho con molino solamente. Esto refleja a primera vista que los propietarios de unidades agrícolas no llegaron a concentrar más de tres propiedades en promedio.

El manejo tipo latifundio de la tierra en el valle no pareció ser la norma en un territorio que concentraba una agricultura intensiva en numerosas propiedades en distintas manos y con fuerte presencia de las comunidades

17 Archivo General de la Nación, Maneyro, Ignacio: Padrón General de españoles, castizos y mestizos de la Villa de Atlixco, 1792, Ramo Padrones, pág. 5. 
de los pueblos de indios. Las crisis mercantiles de finales del XVIII debieron provocar fuertes migraciones en el valle, pero hasta donde sabemos, el carácter "hipotecado" de la villa de Atlixco no es tan evidente, si observamos que el crecimiento de la población en el valle comienza a notarse a lo largo del siglo XIX.

Sigue siendo un tanto misteriosa la historia demográfica de los pueblos de indios, así como su supervivencia a lo largo del siglo XIX en el contexto de epidemias, crisis políticas y económicas importantes. En el valle, las migraciones hacia México y Puebla no impidieron el crecimiento natural de los pueblos en la medida que la recuperación de los negocios de las haciendas, molinos y ranchos reclamaba mayor cantidad de brazos para las faenas propias del ciclo agrícola.

\section{Èlites agrarias y el control de la actividad económica: 1780-1850}

El comportamiento económico de la clase empresarial local entre 1792-1850 fue esencialmente especulativo y rentista; se trataba de una élite ligada al sector primario, escasamente vinculada con el desarrollo de la industria como actividad separada de las actividades agrícolas. Ya el propio Ignacio Maneyro advertía en su informe de febrero de 1792 que "(...) aunque es cierto que sus fincas son supremas en la correspondencia de su cultivo (como después se demostraría) se hallan las más tan agobiadas de gravámenes, que no salen sus dueños de tristes mercenarios de sus fatigas, teniendo más razón para arrepentirse de su prodigalidad, que para quexarse de su desgracia." (p.2)

Pero no todos los miembros de la élite agraria estaban realmente hipotecados. Veamos rápidamente el control de la propiedad y la influencia social de los más importantes de una muestra de los 41 hacendados y comerciantes propietarios a finales del siglo XVIII, como se puede observar en el cuadro de la página siguiente.

Estos 14 propietarios tenían la mayor influencia económica de todo el valle circunscrito al actual territorio del distrito de Atlixco, el de Huaquechula y Calpan. Muy pocos concentraban más de una propiedad y sobre todo ubicada en Atlixco, en menor medida Huaquechula y Calpan, que eran las fronteras indígenas del asentamiento español del "val de Cristo". De los 41 propietarios censados por Ignacio Maneyro, cotejados en buena parte con las transacciones consultadas en el archivo de notarías de Puebla, 28 
SISTEMA DE FÁBRICA EN PAISAJES AGRARIOS MEXICANOS. 1780-1880

HACENDADOS Y COMERCIANTES PROMINENTES DEL VALLE DE ATLIXCO ENTRE 1780-1792

\begin{tabular}{|c|c|c|c|c|c|}
\hline$N .^{\circ}$ & Propietario & Propiedad & Tipo & Lugar & $N^{\circ}$ Propiedades \\
\hline 1 & $\begin{array}{c}\text { Don Antonio Garfias } \\
\text { y Sucs. }\end{array}$ & $\begin{array}{c}\text { Acatzingo } \\
\text { Cantarranas } \\
\text { San Juan } \\
\text { San Miguel }\end{array}$ & $\begin{array}{l}\text { Rancho } \\
\text { Rancho } \\
\text { Hacienda } \\
\text { Hacienda }\end{array}$ & $\begin{array}{c}\text { Atlixco } \\
\text { Huaquechula } \\
\text { Huaquechula } \\
\text { Huaquechula }\end{array}$ & 4 \\
\hline 2 & Lic. Don José Garfias & $\begin{array}{c}\text { Tizayuca } \\
\text { Xalpatlaco } \\
\text { Chilhuacán }\end{array}$ & $\begin{array}{l}\text { Rancho } \\
\text { Hacienda } \\
\text { Hacienda }\end{array}$ & $\begin{array}{l}\text { Atlixco } \\
\text { Atlixco } \\
\text { Atlixco }\end{array}$ & 3 \\
\hline 3 & Don Juan Varela & $\begin{array}{c}\text { San Mateo } \\
\text { Tejaluca } \\
\text { Coyula } \\
\text { Tenextepec }\end{array}$ & $\begin{array}{l}\text { Hacienda } \\
\text { Hacienda } \\
\text { Hacienda } \\
\text { Hacienda }\end{array}$ & $\begin{array}{c}\text { Villa de Atlixco } \\
\text { Atlixco } \\
\text { Huaquechula } \\
\text { Huaquechula }\end{array}$ & 4 \\
\hline 4 & Don José Priorio & $\begin{array}{c}\text { San Diego } \\
\text { la Blanca } \\
\text { La Concepción } \\
\text { La Soledad }\end{array}$ & $\begin{array}{c}\text { Hacienda } \\
\text { Rancho y molino } \\
\text { Rancho }\end{array}$ & $\begin{array}{c}\text { Atlixco } \\
\text { Atlixco } \\
\text { Huaquechula }\end{array}$ & 3 \\
\hline 5 & Don Manuel Caballero & $\begin{array}{l}\text { Buenavista } \\
\text { Tecolotitlán }\end{array}$ & $\begin{array}{l}\text { Hacienda } \\
\text { Hacienda }\end{array}$ & $\begin{array}{l}\text { Atlixco } \\
\text { Atlixco }\end{array}$ & 2 \\
\hline 6 & $\begin{array}{l}\text { Don Bernardo } \\
\text { Rodríguez }\end{array}$ & $\begin{array}{l}\text { San Esteban } \\
\text { San Jerónimo }\end{array}$ & $\begin{array}{l}\text { Rancho } \\
\text { Hacienda }\end{array}$ & $\begin{array}{l}\text { Atlixco } \\
\text { Atlixco }\end{array}$ & 2 \\
\hline 7 & Don Manuel Martínez & $\begin{array}{c}\text { Cabrera } \\
\text { San Diego } \\
\text { Metepec }\end{array}$ & $\begin{array}{l}\text { Hacienda } \\
\text { Hacienda }\end{array}$ & $\begin{array}{c}\text { Atlixco } \\
\text { San Andrés } \\
\text { Calpan }\end{array}$ & 2 \\
\hline 8 & $\begin{array}{c}\text { Marqués de Santa } \\
\text { Martha }\end{array}$ & $\begin{array}{l}\text { San Miguel } \\
\text { Matadero }\end{array}$ & $\begin{array}{c}\text { Hacienda } \\
\text { Rancho y molino }\end{array}$ & $\begin{array}{l}\text { Atlixco } \\
\text { Atlixco }\end{array}$ & 2 \\
\hline 9 & Don Mariano Jiménez & $\begin{array}{c}\text { Tepepan } \\
\text { Coatzingo }\end{array}$ & $\begin{array}{l}\text { Rancho } \\
\text { Rancho }\end{array}$ & $\begin{array}{l}\text { Huaquechula } \\
\text { Huaquechula }\end{array}$ & 2 \\
\hline 10 & Don Antonio Márquez & $\begin{array}{l}\text { Zapotitlán } \\
\text { La Trapera }\end{array}$ & $\begin{array}{l}\text { Hacienda } \\
\text { Hacienda }\end{array}$ & $\begin{array}{l}\text { Huaquechula } \\
\text { Huaquechula }\end{array}$ & 2 \\
\hline 11 & $\begin{array}{l}\text { Don José Pinto } \\
\text { Del Águila }\end{array}$ & $\begin{array}{c}\text { Ixtlatlala } \\
\text { y Baños } \\
\text { San Nicolás }\end{array}$ & $\begin{array}{l}\text { Hacienda con } \\
\text { rancho } \\
\text { Hacienda con } \\
\text { rancho }\end{array}$ & $\begin{array}{l}\text { Huaquechula } \\
\text { Huaquechula }\end{array}$ & 2 \\
\hline 12 & $\begin{array}{l}\text { Lic. Don Cristóbal } \\
\text { González }\end{array}$ & $\begin{array}{c}\text { San Bartolomé } \\
\text { San José }\end{array}$ & $\begin{array}{l}\text { Hacienda } \\
\text { Hacienda }\end{array}$ & $\begin{array}{l}\text { San Andrés } \\
\text { Calpan } \\
\text { San Andrés } \\
\text { Calpan }\end{array}$ & 2 \\
\hline 13 & Don Joaquín Hidalgo & La Candelaria & $\begin{array}{l}\text { Rancho } \\
\text { y molino }\end{array}$ & Atlixco & 1 \\
\hline 14 & $\begin{array}{c}\text { Don Juan Sánchez } \\
\text { Vizcaíno }\end{array}$ & El Cristo & $\begin{array}{l}\text { Rancho } \\
\text { y molino }\end{array}$ & Atlixco & 1 \\
\hline
\end{tabular}


tenían una sola propiedad agrícola, de los cuales sólo dos contemplaban en su rancho la instalación de un molino de harinas, por esta razón los agregamos a la lista de los 14 más prominentes de la región.

Mención aparte merece el único caso de una propiedad agraria que no aparece censada dentro del hinterland agrario de la villa de Atlixco ni del tenientazgo de Calpan y el pueblo de Huaquechula. La hacienda de San Mateo formaba parte de la mancha urbana de la villa, circundando la antigua calle de la carnicería, muy cerca de la Plaza Mayor. Al formar parte del cuadro urbano de Atlixco, San Mateo adquirió una importancia capital en el abasto inmediato de granos para la ciudad y aunque el censo de 1792 no consigna todavía el molino de trigo, es ya conocido que en el interior de la finca se construyó el molino de harinas de trigo más importante del valle en una sola unidad agrícola. El dueño de San Mateo, aparentemente soltero, era nada menos que Don Juan Varela, quien administraba la finca en compañía de una hermana casada, además de un criado y mayordomo, todo ellos españoles con excepción de la mujer del mayordomo que aparece ya registrada como mestiza.

Dado que la familia Garfias aparece a finales del siglo XVIII como la de mayor importancia por la suma de los bienes agrícolas que poseían, a Juan Varela lo ubicamos como al tercer propietario individual de gran importancia en la villa. El propio Maneyro, al hacer mención de las características de la Parroquia de Españoles de la Plaza Mayor de la Villa, nos muestra el carácter filantrópico de José Garfias:

\footnotetext{
"(..)tiene a su cuidado el aseo de la Iglesia, y es responsable de sus alajas, que las tiene muy ricas en Vasos sagrados, y Ornamentos, y una sumptuosa Lampara, (...) de plata, que la piedad, y christianos sentimientos del Licenciado Don José Garfias Presbítero avencidado en esta Villa, y Abogado de la Real Audiencia con otros costosos adornos, dignos de su Vizarría, ha cedido en obsequio, y gratitud de la Religión, que abrazó en su pila baptismal.” ( p.2)
}

La estrecha relación entre propiedad agraria y funciones públicas o eclesiásticas era la norma dentro del privilegiado grupo de la élite provincial. Don Juan Sánchez Vizcaíno, propietario del rancho y molino de El Cristo, en la jurisdicción de la villa, tenía un hermano, José, dueño de la hacienda de Portezuelo, y otro, Pedro, quien fungía como escribano real en la notaría de Atlixco en el año de 1773. Esto significa que dentro de la élite económica de Atlixco los hacendados y rancheros molineros tenían un lugar destacado tanto en el ámbito local como intrarregional. 
En resumen, después de una revisión de inventarios y declaraciones notariales, durante la primera mitad del XIX las haciendas del valle continuarían sobreviviendo con la misma lógica de la economía virreinal con la salvedad de que los arrendamientos, el traspaso de manos, el acceso a tomas de aguas y el control de la mano de obra se intensificaría enormemente. Como ejemplo representativo de la continuidad de los negocios regionales en la primera mitad del siglo XIX tenemos el caso de la prominente familia de Lorenzo Lozano de Alarcón y sus hermanos, tomando en cuenta que sus negocios se iniciaron desde mediados del siglo XVIII, vinculados a la familia de la futura esposa de Estevan de Antuñano. En el análisis de 57 documentos notariales los negocios del Capitán Lorenzo Lozano de Alarcón y sus hermanos José María y Joaquín se distribuyeron así:

\begin{tabular}{|c|c|c|c|c|c|c|c|}
\hline Empresario & $\begin{array}{c}\text { Operaciones } \\
\text { registradas }\end{array}$ & Comercio & Concesiones & $\begin{array}{c}\text { Créditos e } \\
\text { hipotecas }\end{array}$ & Industria & Inmuebles & $\begin{array}{c}\text { Haciendas } \\
\text { ranchos }\end{array}$ \\
\hline $\begin{array}{c}\text { Lorenzo y José } \\
\text { María Lozano } \\
\text { de Alarcón }\end{array}$ & $\begin{array}{c}57 \\
(1815-1849)\end{array}$ & 3 & 0 & 22 & 0 & 4 & 19 \\
\hline
\end{tabular}

Además de estas actividades, tanto Lorenzo como José María fueron varias veces funcionarios públicos del Cabildo atlixquense. En 1819, Don Lorenzo fue regidor provincial. En 1822 aparece ya como alcalde primero, subdelegado del partido y escribano suplente. En 1825 es consejero superior del gobierno del nuevo Estado de Puebla. Su hermano Joaquín era sacerdote y su heredero en varias propiedades. José María fue regidor en 1832. En síntesis, su fortuna durante la primera mitad del siglo XIX representa muy bien los negocios de la élite agraria: participación en el poder político y prestamistas en operaciones de crédito y financiamiento a la producción o rentas en el sector primario. El segundo rubro de gran participación es el de la adquisición o arrendamiento de haciendas y ranchos, ya que algunas de estas propiedades fueron a la vez subarrendadas o revendidas a terceros.

En los negocios de este grupo representativo de la élite en la primera mitad del siglo XIX no se observa la incursión en la creación de un espacio fabril. Si en el informe de Ignacio Maneyro, en 1792, por cada 2000 habitantes censados en la jurisdicción del partido de Atlixco (con el pueblo

18 AGN-Atlixco 1815-1850. Información gentilmente proporcionada por el Ingeniero Ramón Lozano, descendiente de la familia. 
de Calpan incluido) había 30 tejedores promedio, entre españoles, mestizos y castas, de un total de 6000 censados, habría aproximadamente 90 tejedores. La situación no pareció variar mucho en los siguientes cincuenta años, excepto que en los pueblos y en las haciendas, los "operarios" agrícolas eran a la vez hilanderas (os) y tejedores para sus comunidades. Es este microespacio manufacturero, el que las élites agrarias tratarán de ganar y expandir un tanto influidas por las tesis de la insurrección industrial de Estevan de Antuñano desde 1835, con la creación de su famosa "Constancia Mexicana" y el Banco de Avío de Lucas Alamán.

Generalmente se concibe en forma errónea la idea de que la empresa mexicana o latinoamericana se inserta en un paisaje cultural típicamente europeo (revolución agrícola, revolución demográfica y migración campociudad). Las empresas mexicanas siguieron básicamente dos modelos de localización en el siglo XIX: el de los reales de minas (que eran empresas mineras, cuyos restos debían ser rescatados como empresas de "antiguo régimen") y el de las haciendas cerealeras y azucareras en segundo término. No hay una teoría de la empresa en los países periféricos, de allí que sea confuso distinguir qué caracterizó a una empresa del antiguo régimen virreinal (incluso prehispánico) y cuándo y cómo surgen las modernas empresas. Para México, hacer historia de empresas significa hacer historia de las minas y de las haciendas como empresas, y cómo el sector manufacturero intentó copiar su ejemplo para convertirse en industria de "punta" en el siglo XIX. ${ }^{19}$

Resulta un tanto paradójico que la totalidad de la élite empresarial de la región agrícola del Valle de Atlixco entre 1815-1880 no tuviera una vinculación directa con los negocios fabriles a pesar de los antecedentes virreinales ya citados aquí y de la rápida proliferación de fábricas después de 1852, bajo el control de industriales "arrendatarios" avecindados en la ciudad de Puebla. El antecedente importante de la implantación del sistema fabril en Atlixco lo tenemos justo a mediados del siglo XIX, cuando en la memoria del gobernador de Puebla, Juan Mújica y Osorio ${ }^{20}$ de 1849 , se hace mención que éste, interesado en el negocio textil por influencia de sus amigos empresarios poblanos como Joaquín de Haro y Tamariz, proporcionó la hilaza, y José María Rodiles, el apoderado de los negocios de José

19 Cfr. los trabajos de Mario Trujillo, Mariano Torres y Rocío Ruíz de la Barrera publicados en Marichal, Carlos: Historia de las Grandes Empresas en México, 1850-1930, FCE, México, 1997. Son los únicos que pretenden mostrar este puente entre el "ancien régime" colonial y el siglo XIX. 20 Mújica y Osorio, Juan: Memoria, 1849. 
María Alarcón, hacendado de tradición en Atlixco, los telares para habilitar y formar un taller de tejidos en Atlixco. No sabemos si dicho taller funcionó y hasta cuándo, pero en la memoria se hace mención —en el anexo estadístico- de la existencia de una fábrica de hilados de algodón en Atlixco llamada "Providencia de Atlixco", cuyo propietario fue Manuel Carranza. Dicha fábrica registraba 1,320 husos, con una producción de 98 mil 800 libras de hilaza al año, sin embargo, en realidad era pequeña en comparación con la mayoría de las fábricas de Puebla. Probablemente abastecía de hilos a los talleres que, como el que instalaron Mújica y Rodiles, se destinaban a la producción de tejidos. Debió desaparecer o transformarse muy rápido, pues no vuelve a aparecer en ninguna estadística local y nacional.

Mújica y Osorio fue un gobernante que apoyó en gran medida al desarrollo de Atlixco. Durante su administración, Tochimilco se incorporó definitivamente a la jurisdicción de Atlixco, y se fundó dentro del departamento, con sede en la ciudad de Atlixco, la octava prefectura de Puebla separada administrativamente de Matamoros. Impulsó el camino de Puebla a Matamoros vía Atlixco como parte de un proyecto ambicioso que tenía como finalidad desarrollar la comunicación interoceánica de Puebla. El interés en un negocio textil por parte de Mújica y Osorio en la región de Atlixco no era una simple afición, pues su experiencia como empresario venía de tiempo atrás. Para el año de la memoria, Mújica era dueño de la fábrica del "Carmen" en Puebla con 2,080 husos y una producción de hilaza al año de 90,545 piezas. Para 1857 Mújica contaba con una fábrica de velas y esterina en Puebla, que debió ser muy próspera ya que en la relación de las distinciones y premios que registra la Memoria de Fomento de aquel año sus productos alcanzaron un premio de tercera clase. Mújica fue un firme partidario de las políticas correccionales para abastecer de trabajadores a las fábricas regionales. Consideraba que los correctivos de la vida laboral en el campo podían ser aplicados a las fábricas textiles. En Matamoros el prefecto de la época daba nota de que la cárcel se había convertido en un taller para oficios varios que incluía obviamente el de tejidos. Como empresario, Mújica fue partidario de las ideas de Alamán y de Antuñano y manifestó en sus escritos una profunda preocupación por el duro golpe que la invasión norteamericana había dado a la industria textil local, con precios al alza del algodón.

Volviendo al desarrollo inicial de la industria fabril en Atlixco, observamos que en la estadística de las fábricas de hilados y tejidos de algodón a 
nivel nacional de $1857^{21}$ aparece una información que puede arrojar luz sobre la presumible existencia de fábricas en Atlixco anteriores a "La Concepción". Se menciona como de Atlixco a la fábrica de "El Patriotismo" de Velasco y Cía. "La Providencia" aparece como una fábrica de Puebla en manos de un tal Francisco Caballero de Carranza, probablemente emparentado con Manuel Carranza que aparece como propietario de "La Providencia" de Atlixco, en la estadística de Mújica y Osorio. Seguramente los cambios en la nomenclatura territorial se deban a que en estos años el reacomodo de las "fronteras locales" heredadas del virreinato experimentó una serie de desincorporaciones de tierras que pertenecían a Atlixco y que pasaron al ámbito regional de Puebla capital pues, por ejemplo, "El Patriotismo" se encontraba en las afueras, en las márgenes del río Atoyac, justo en uno de los caminos antiguos a Atlixco. Es probable que la fábrica "La Providencia", que se ubica en Cholula para las estadísticas de $1890,{ }^{22}$ sea la misma que originalmente se encontraba bajo jurisdicción de Atlixco y luego de Puebla.

\section{El carácter marginal y arrendatario del camino a la fábrica}

En otro estudio he demostrado que los problemas con el agua y con el flujo de trabajadores contribuyeron a que las inversiones de hacendados, molineros, comerciantes e industriales retardaran su interés por la industria textil en Atlixco después de la fundación de la fábrica de "La Concepción"(1852), hasta 1865-1870. En este lapso, proliferaron los talleres donde se tejía con telares de bimbaletes las telas de manta tipo "cabeza de indio". ${ }^{23}$

En el siglo XIX, las primeras fábricas textiles de Atlixco hacia 18521870 se fundaron sobre el arrendamiento de tierras, aguas y edificios de molinos de trigo para construir fábricas modernas, con complicados sistemas de control "ecológico" en el uso y distribución de las aguas de riego de haciendas, pueblos y ranchos.

Es el caso de la sociedad formada por Don Manuel García Teruel y Don Francisco Cabrera, con fecha 9 de agosto de 1864. El objetivo era establecer una fábrica de hilados y tejidos de algodón en los terrenos del moli-

21 Siliceo, Manuel: Memoria de Fomento, 1857.

22 Cuadro de fábricas de la República Mexicana en Directorio estadístico de la República Mexicana, Imp. La Europea, México, 1889.

23 Sánchez Flores, Ramón: "Arqueología industrial en el valle de Atlixco", en Simposium internacional..., pág. 193. 
no de "la Candelaria" de Atlixco, propiedad del señor Cabrera, que participaría con un tercio del capital. El total de la inversión fue de 108 mil pesos entre especie y efectivo repartido de la siguiente forma:

COSTOS DE OPERACIÓN DE UNA NUEVA COMPAÑÍA TEXTIL EN 1864 (haciendas, aguas y molinos de trigo) Sociedad Cabrera y García Teruel

\begin{tabular}{|c|c|c|}
\hline Propietario & Bienes de Capital Social & Valor \\
\hline Francisco Cabrera & $\begin{array}{c}\text { Molino de trigo de "La Candelaria" (edifi- } \\
\text { cios, aguas, etc.) }\end{array}$ & $\$ 36,000.00 \mathrm{M} . \mathrm{N}$. \\
\hline \multirow[t]{19}{*}{ Manuel García Teruel } & $\begin{array}{l}12 \text { tróciles Damfost de } 132 \text { husos, } \\
\text { dando un total de } 1584 \text { husos. } \\
\text { Valuados a } 5 \text { pesos cada uno. }\end{array}$ & $\$ 7,920.00$ M. N. \\
\hline & $\begin{array}{l}6 \text { mulas de } 300 \text { husos cada una, dan un total } \\
\text { de } 1800 \text { valuados a } 2.5 \text { pesos. }\end{array}$ & $\$ 4,500.00$ M. N. \\
\hline & 1 Batiente superior de tres volantes & $\$ 1,200.00$ M. N. \\
\hline & $\begin{array}{l}20 \text { Cardas con sus vestiduras en uso } \\
\text { a } 300 \text { pesos cada una }\end{array}$ & $\$ 6,000.00$ M. N. \\
\hline & 2 Cabeceras para 16 cardas & $\$ 500.00$ M. N. \\
\hline & 1 Cabecera para 4 cardas & $\$ 200.00$ M. N. \\
\hline & 1 Amolador de carda & $\$ 100.00$ M. N. \\
\hline & 4 Estiradoras a 350 pesos cada una & $\$ 1,400.00$ M. N. \\
\hline & 4 veloces a 300 pesos cada uno & $\$ 1,200.00$ M. N \\
\hline & 1 Carretero & $\$ 100.00$ M. N. \\
\hline & 3 Urdidores con sus llaves a $\$ 50$ cada uno & $\$ 150.00 \mathrm{M} . \mathrm{N}$. \\
\hline & $\begin{array}{c}5 \text { devanaderas con armazón de fierro } \\
\text { a } \$ 60 \text { cada una }\end{array}$ & $\$ 300.00$ M. N. \\
\hline & 5 devanaderas de madera a $\$ 15$ cada una & $\$ 75.00 \mathrm{M} . \mathrm{N}$. \\
\hline & 1 Volero para pabilo & $\$ 100.00$ M. N. \\
\hline & 1 Prensa para paquetes & $\$ 80.00$ M. N. \\
\hline & 1 Torno & $\$ 100.00$ M. N. \\
\hline & $\begin{array}{l}80 \text { Telares ingleses con sus aviaduras } \\
\text { a } 250 \text { cada uno }\end{array}$ & $\$ 20,000.00$ M. N. \\
\hline & $\begin{array}{l}\text { Flechas para el movimiento de máquinas, } \\
\text { empalmes, colgaduras, tornillos, poleas } \\
\text { y piñones con piezas de refacción }\end{array}$ & $\$ 8,000.00$ M. N. \\
\hline & $\begin{array}{l}\text { Una rueda superior suficiente como } \\
\text { para mover toda la maquinaria }\end{array}$ & $\$ 8,000.00$ M. N. \\
\hline $\begin{array}{l}\text { Valor total de la maquinaria: } \\
\text { con botes, carretes, etc. }\end{array}$ & & $\$ 59,925.00$ M. N. \\
\hline Aportación en efectivo & & $\$ 12,075.00 \mathrm{M} . \mathrm{N}$. \\
\hline Capital inicial de García Teruel: & & $\$ 72,000.00$ M. N. \\
\hline Capital Social: & & $\$ 108,000.00$ M. N. \\
\hline
\end{tabular}


Es interesante observar que la rueda de tracción para la fuerza motriz tenía un costo similar al de una rueda de molino normal. Puede inferirse que quizá usaban la misma rueda hidráulica.

Si García Teruel aumentaba la cantidad de máquinas en acuerdo con el Sr. Cabrera, se debía deducir el valor de dichas máquinas del efectivo aportado. En proporción a dos tercios y un tercio de capitales respectivos, aportarían los socios las cantidades necesarias para trasladar la maquinaria de la pequeña fábrica textil, que estaba en Jalapa, "La Bella Unión Jalapeña" propiedad de Manuel García Teruel.

Los edificios del molino de "La Candelaria" debían terminar sus trabajos de limpieza en octubre, y quedar libres para instalar la maquinaria. Para poder ser socio, Francisco Cabrera vendió el molino de la Candelaria en 30 mil pesos al Sr. García Teruel, pagaderos en tres partes: el primer año 10 mil pesos, el segundo otros 10 mil y al terminar la sociedad los últimos 10 mil. Estos pagos anuales causaron un interés del 6\% anual. El valor del terreno donde está el Jagüey de la Concepción y que pertenece a "La Candelaria" (50 varas en cuadro por el viento que eligiese el señor Cabrera) sería satisfecho a García Teruel o en cambio por otro terreno similar. Esto dejaría al Jagüey y a las 50 varas de terreno en propiedad de la fábrica de "La Concepción", que se encontraba río debajo de la nueva toma de la futura fábrica textil. Esta última constaría de 3,380 husos y 80 telares movidos con la fuerza motriz del propio molino. El valor total de la inversión inicial ascendió a los 125,925 pesos, incluido el valor del molino, la maquinaria y los 30,000 pesos en efectivo. ${ }^{24} \mathrm{El} 4$ de agosto de 1870 se disolvió la sociedad y Francisco Cabrera acabó vendiendo, como ya lo mencionamos, el molino de "La Candelaria" al Sr. García Teruel con todas sus tierras, aguas y servidumbres. Esta inversión daría origen a la fábrica textil de "La Carolina". ${ }^{25}$

Como antecedente de la fundación de la fábrica textil de "La Concepción" es importante hacer notar que ésta se construyó en terrenos desagregados del rancho de Chapulapa, propiedad del Sr. Ignacio Guerrero. La sociedad de los señores Cabrera y Bello tomó el control de la fábrica de hilados de algodón en los "suburbios" de la ciudad de Atlixco. Incluyó una parte de las tierras y toda el agua que utilizaba el molino de San Mateo, calculada en 12 surcos. Esta agua podía usarla la fábrica para mover su maqui-

24 AGNP, Notaria No. 5. Protocolos de 1864, ff. 268v y ss.

25 AGNP, Notaria No. 5, Protocolos de 1870, ff. 204 y ss. 
naria sin detrimento de tiempo y con 6 surcos dominicales para regar las tierras anexas. No se anotó en la escritura de compraventa servidumbre alguna para las aguas. Los compradores hicieron uso de sus derechos y encontraron un "ladrón" en el acueducto de la fábrica, más de un surco, que daba al vecindario. Don José García se presentó diciendo que tenía derecho cada 20 días de disponer del surco para regar un solar de su propiedad. Posteriormente se presentaron los dueños de la hacienda de la Sabana para protestar alegando que los 12 surcos de agua de Chapulapa vendidos a la fábrica les pertenecían conjuntamente con San Mateo; desde las 6 de la tarde hasta las 6 de la mañana del siguiente día de la Pascua de Navidad hasta la "entrada de las aguas". Se exceptuaban 5 surcos para los miércoles y sábados y 7 surcos los sábados y otro cualquier día de la semana que por lo pronto se fijó en viernes. Los compradores exigieron al vendedor arreglar y sanear la situación, aun en grave perjuicio de sus intereses acordando desde el mes de agosto de 1870 lo siguiente:

1) Don Ignacio Guerrero continuará con los terrenos que le asignen los señores Cabrera y Bello con derecho a un tanque o depósito de 150 mil pies cúbicos conforme le indiquen.

2) La fábrica tendrá derecho a disponer en ese tanque del agua que corra, durante los tiempos de descanso de la comida de los obreros, por su acueducto, con objeto de suplir en ese depósito en las primeras horas de la noche la falta de agua que toma la hacienda de la Sabana.

3) La fábrica podrá detener hasta llenar el tanque a partir de las 10 de la noche en adelante, los 7 surcos las noches de los viernes y sábados que la hacienda de la Sabana tiene que dejar al molino de San Mateo y el rancho de Chapulapa.

Se trataba de suplir, en las cuatro primeras horas de la noche, de agua a la hacienda de la Sabana. Se entiende que la fábrica disponía del derecho de depositar en el estanque, a cualquier hora, la parte del agua que no necesitase hacer pasar "por su rueda" hasta llenarlo, dejándola pasar como siempre, una vez llenado el tanque.

Para 1870 Manuel García Teruel, hacendado arraigado en el sur del Valle en los límites con Matamoros, con explotaciones azucareras en torno a la famosa hacienda de Matlala, tenía ya en operación la segunda fábrica textil de Atlixco, llamada "La Carolina". Esta fábrica fue la primera que se estableció al amparo de las caídas de agua del río de San Baltazar un tanto al sur de donde se ubicaba "La Concepción". Con esta fábrica se desata una 
política de impuestos regionales que hostilizó gravemente a las haciendas, molinos y a las dos fábricas textiles que funcionaban plenamente. García Teruel invirtió una buena suma logrando que para 1877 la "Carolina" fuera la segunda fábrica más grande de Puebla después del "Patriotismo", en cuanto al número de trabajadores empleados. ${ }^{26}$ Pero Manuel García Teruel pertenecía a una tradición empresarial diferente a la de origen virreinal regional. Su intrusión en el paisaje agrario de Atlixco se explica por su carácter de "arrendatario" de molinos de trigo y de surcos de agua de haciendas prósperas de la región que le permitieron montar fábricas textiles modernas, negocios en los que la élite agraria no había manifestado interés alguno desde el virreinato.

¿Cuáles eran, entonces, los negocios dominantes de la élite local a lo largo del siglo XIX?

De los más de 450 miembros de la élite ${ }^{27}$ mercantil y propietaria que hubo en la región entre 1850-1880, 22 se declararon abiertamente como comerciantes propietarios, 3 como propiamente industriales, 8 como labradores, agricultores arrendatarios y propietarios, uno manifestó ser regidor, 3 administradores de rentas e hipotecas, 13 religiosos entre presbíteros y sacerdotes, 9 notarios, 3 abogados, un empleado público, un dependiente de mostrador. Evidentemente la base de datos requiere una depuración mayor ya que estos datos denotan solamente la frecuencia con la que acudieron a realizar transacciones notariales en el periodo indicado, además de ser una muestra no estadística sobre el total de expedientes notariales. Muchos de los comparecientes no declaran su ocupación posiblemente porque eran miembros de un clan familiar, cuya cabeza sí registra claramente sus giros de negocios. Las mujeres también tienden a ocultar sus ocupaciones, excepto las que claramente son propietarias de bienes inmuebles o realizan actividades religiosas.

En cuanto a las operaciones realizadas ante notario: 24 intervinieron como prestamistas, 76 en hipotecas, 167 en operaciones de compraventa, 25 en sucesiones testamentarias, 53 hicieron su testamento y 24 participaron en fundaciones de sociedades mercantiles tipo industrial hacia finales del periodo de observación: 1870-1880.

26 Busto, Emiliano: Estadística de la República Mexicana, Imp. I. Cumplido, anexo 3 de la Memoria de Hacienda, 3 vols., 1880.

27 Véase Archivo General de Notarías de Puebla. Notarios de Atlixco. Años: 1850, 1852, 1856, 1860, 1862, 1864, 1870, 1872, 1876, 1880, 1885, 1890. 
Queda claramente delineada una actitud empresarial de "antiguo régimen" donde el comercio, el control de la propiedad raíz y las haciendas, el control del escaso circulante a través de préstamos e hipotecas y su carácter asociativo con empresarios "emprendedores" venidos de Puebla y México para negocios mercantiles de tipo fabril muestran que una de las consecuencias históricas del peso enorme de la inseguridad institucional para fomentar inversiones de riesgo, la descapitalización permanente de ayuntamientos y productores obligó a la élite agraria de origen virreinal a retener capitales líquidos y propiedades en maniobras rentistas, especulativas, diversificando el radio de acción de sus inversiones en negocios de alta plusvalía y riesgo menor, donde las "empresas" propiamente fabriles quedaron en manos de aventureros foráneos que no tenían claridad sobre las ganancias que dichos giros podían reportarles..$^{28}$

Como conclusión preliminar podemos afirmar que en estos 100 años de transformación de la sociedad virreinal a la secular e independiente, el México agrario en el altiplano de los valles centrales no modificó radicalmente las estrategias de reproducción del capital de inversión en proyectos productivos rentables, fuera del ámbito del rentismo, la especulación y el comercio local. La industria moderna es concebida como un apéndice de otros negocios más rentables y seguros, y sólo con la llegada de élites foráneas, que utilizaron las ventajas tecnológicas del paisaje agrario regional, lograron dar "el salto" y convertirse paradójicamente en arrendatarios regionales de unidades productivas que paulatinamente transformaron en modernas fábricas textiles. La notable persistencia de un paisaje agrario "pre y proto" industrial junto con el incipiente sistema fabril se convirtió más en la norma que en la excepción del modelo mexicano de industrialización heredado desde el siglo XIX.

28 Algunas partes de este ensayo han sido publicadas para complementar estudios colaterales al tema aquí tratado. Véase en particular "Una historia económica regional a partir de la industrialización mexicana en el siglo XIX", en Bogumila Lisocka Jaegermann: El Espacio en la Cultura Latinoamericana, Cesla, Varsovia, 2001, págs. 30-42. "El Modelo Hacienda-Fábrica en los orígenes de la industrialización mexicana", en Memoria del 2. ${ }^{\circ}$ Encuentro Nacional de Conservación del Patrimonio Industrial, CMCPI- U de G., U. A. de Aguascalientes. 2002, "La Historiografìa económica de las empresas mexicanas a través de sus archivos", en Historia y Grafía, Revista de Historia de la UIA-Santa Fe, N. ${ }^{\text {a } 15-2000, ~ p a ́ g s . ~ 269-300 . ~ T a m b i e ́ n ~ e l ~ i n e ́ d i t o ~ " L a s ~ d i s p u t a s ~ p o r ~ e l ~ c o n t r o l ~ d e l ~ a g u a ~ e n ~}$ paisajes agrarios mexicanos: haciendas, molinos de trigo y fábricas textiles (1780-1850)", en 51 ICA, Santiago de Chile, 2003. 